\title{
Utilização da biomassa como energia alternativa
}

\section{Biomass as alternative energy}

\author{
Murilo Henrique Ribeiro ${ }^{1}$, Lucimara Bianco ${ }^{2}$
}

${ }^{1}$ Aluno de Graduação do curso de Engenharia de Produção. Centro Fundação Educacional de Barretos, bolsista pelo programa Pro Uni (2013).E-mail: murilo0610@hotmail.com

${ }^{2}$ Mestre em Engenharia de Produção Universidade de São Paulo, professora coordenadora do curso de Engenharia de Produção do Centro Fundação Educacional de Barretos. E-mail: bianco.lucimara@ig.com.br

\section{Resumo}

Energia de biomassa é gerada por meio da decomposição de materiais orgânicos (esterco, restos de alimentos, resíduos agrícolas), que produzem o gás metano utilizado para a geração de energia. Para fazê-la são utilizados materiais como biomassa arborícola, sobra de serragem, vegetais e frutas, bagaço de cana e alguns tipos de esgoto. A biomassa é transformada em energia por intermédio dos processos de combustão, gaseificação, fermentação e também produção de substâncias líquidas.

Palavras-chave: Biomassa, Energia Renovável, Sustentabilidade.

\begin{abstract}
Biomass energy is generated through the decomposition of organic materials (manure, food waste, agricultural waste), producing methane, which is used for the generation of energy. To do this, materials such as arboreal biomass, sawdust, vegetables and fruits, bagasse and some types of sewage are used. Biomass is transformed into energy through the processes of combustion, gasification, fermentation and also in the production of liquid substances
\end{abstract}

Keywords: Biomass, Renewable Energy, Sustainability.

Autor para correspondência: Murilo Henrique Ribeiro - Curso de Engenharia de Produção, Centro Universitário da Fundação Educacional de Barretos (UNIFEB) - Barretos (SP), Brasil. muriloplagil@gmail.com Recebido em: 27 de março de 2017

Aceito em: 22 de setembro de 2018 


\section{Introdução}

A biomassa é fonte de energia renovável que utiliza a matéria orgânica para a obtenção de energia. Essa matéria orgânica pode ter por origem a limpeza das florestas, os resíduos da agropecuária, das usinas de açúcar e álcool, da indústria alimentar ou os resíduos consequentes do tratamento de efluentes domésticos ou industriais.

A biomassa, conhecida também como massa biológica, é a quantia de matéria orgânica gerada em uma determinada área. Esse termo tem sito muito empregado nos últimos anos, em função das preocupações relacionadas às fontes de energia e também a sustentabilidade. A biomassa pode gerar gases que são transformados, em usinas específicas, em energia.

Devido a crescente preocupação mundial em aumentar o uso de energia de fontes renováveis, os resíduos das mais variáveis origens despontam como interessantes alternativas energéticas (NOGUEIRA; LORA, 2003).

Essa energia é resultado da decomposição de materiais orgânicos como, por exemplo, esterco, bagaço da cana-de-açúcar, madeira, resíduos agrícolas, restos de alimentos, entre outros. Além disso, podemos aproveitar mais os resíduos agroindustriais e biomassas que são gerados em prazos curtos comparados a outras matérias orgânicas citadas acima e também de baixo custo, assim complementam ou substituem a madeira como fonte de energia. Reúnem-se, portanto, as condições necessárias para dar um novo impulso ao uso dessas fontes renováveis cujos custos tendem a decrescer, ao contrário das expectativas dos combustíveis fósseis, que tendem a ficar mais insuficientes ao longo dos anos.

A Figura 1 demonstra, de acordo com estudos realizados pela ANEEL, que a produção de energia com a utilização da biomassa vem se destacando:

O objetivo do estudo é obter uma visão global do uso de biomassa nos setores industriais e de transporte e obter a lista dos maiores usuários de energia de biomassa no mundo. A pesquisa utilizou dados de várias fontes em todo o mundo. No Brasil, foram coletadas informações do balanço anual de oferta e consumo de energia publicada pelo Ministério de Minas e Energia, dos bancos de dados da União da Indústria de Cana-de-Açúcar (UNICA), da União dos Produtores de Bioenergia (UDOP) e da Agência Nacional do Petróleo, Gás Natural e Biocombustíveis (ANP).

\section{Materiais e métodos}

$\mathrm{Na}$ história, a biomassa acabou perdendo sua liderança para a energia do carvão (segunda fonte de energia mais utilizada no mundo depois do carvão) e, posteriormente, com o crescimento contínuo do uso de petróleo e do gás natural, a utilização da biomassa foi reduzida. Porém, hoje, em maior ou menor intensidade, a maioria dos

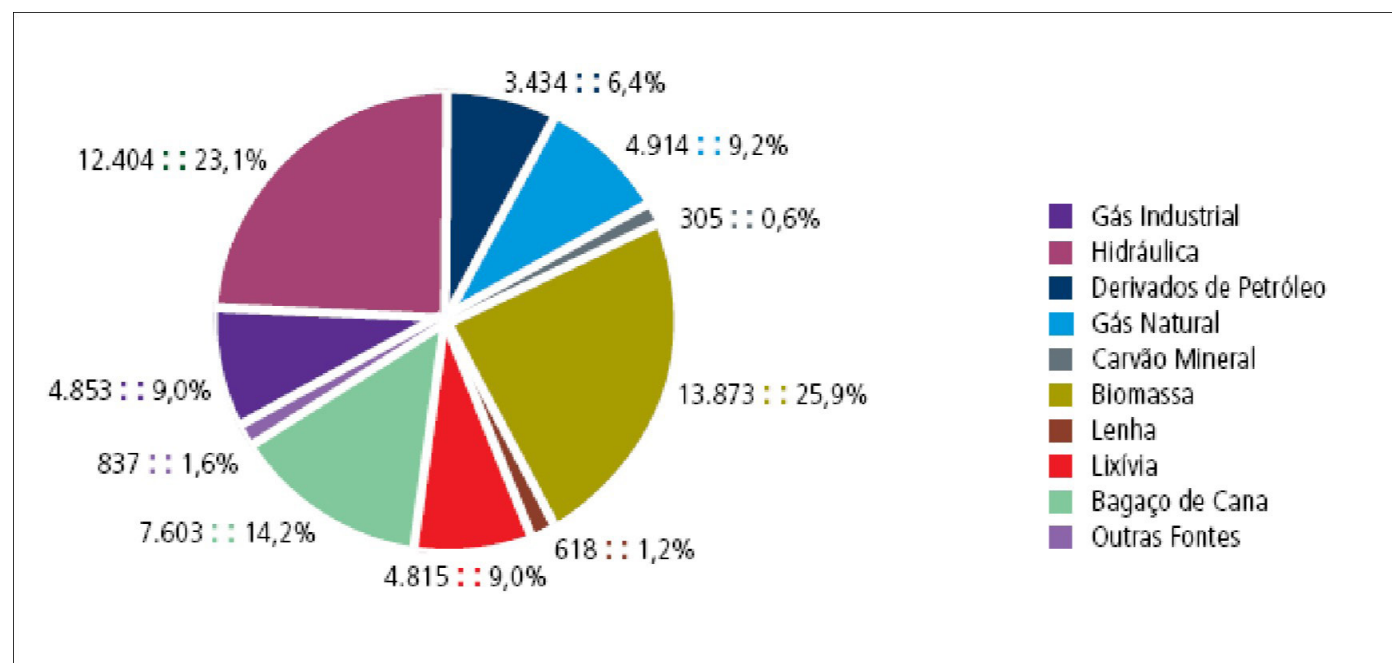

Figura 1. Geração de energia elétrica - Autoprodução (total e participação por fonte - Brasil, 2008) Fonte: Atlas de energia Elétrica do Brasil (2008) 
países, desenvolvidos ou não, está promovendo ações para que as energias alternativas renováveis tenham participação significativa em suas matrizes energéticas.

Das fontes energéticas renováveis, somente a biomassa possui a flexibilidade de suprir tanto a produção de energia elétrica quanto para mover o setor de transporte. Em 2012, a biomassa ocupou o terceiro lugar nas fontes de geração de energia elétrica, $6,8 \%$ do total da energia gerada, atrás apenas da energia hidroelétrica e da energia gerada através do gás natural (AGÊNCIA NACIONAL DE ENERGIA ELÉTRICA, 2012).

De acordo com o Banco Mundial, 50\% a 60\% da energia nos países em desenvolvimento vêm da biomassa, e metade da população mundial cozinha com madeira. A geração de energia por queima da madeira cresceu de 200 megawatts em 1980 para 7.800 megawatts atualmente (BALEOTTI, 2007).

Existem também formas de produção de substâncias líquidas a partir de um material que seja vegetal. Ela pode ser realizada de duas formas: conversão biológica, na qual os açúcares da cana são modificados por bactérias para etanol. E a conversão térmica, que ocorre quando o material vegetal se decompõe sem a presença do oxigênio na presença de um forte calor. Nesse processo pode acontecer a produção de combustíveis líquidos e gasosos.
"Na primeira metade da década de 1980, houve a elevação do uso industrial de biomassa devido à substituição do óleo combustível por carvão vegetal, à produção de álcool, utilizando-se o bagaço de cana-de-açúcar, e à expansão da siderurgia a carvão vegetal. Seu consumo nos setores residencial e agropecuário decai, devido a menor utilização da lenha para cocção (INNOCENTE, 2011) (Tabela 1).

Processo de conversão da biomassa: Existem três formas de transformar a biomassa em energia: Combustão: Libera o calor para a produção de eletricidade por intermédio da biomassa, que pode ser utilizada em usinas de carvão. Na indústria de madeira é normalmente usada a combustão de restos de madeira para a geração de calor e eletricidade. Combustão direta é a transformação da energia química dos combustíveis em calor, através das reações dos elementos constituintes com o oxigênio fornecido. A combustão direta realiza-se essencialmente em fogões, fornos e caldeiras. Aqui, a queima da biomassa é executada em altas temperaturas, com a presença excessiva de oxigênio, produzindo vapor a alta pressão. Esse vapor geralmente produzido é usado nas caldeiras ou para mover turbinas. É um dos métodos mais comuns utilizados hoje em dia e sua eficiência energética situa-se na faixa de $20 \%$ a $25 \%$. A Figura 2 mostra os principais processos de conversão energética da biomassa.



Figura 2. Processo de conversão energética da biomassa 
Tabela 1. Classe de combustíveis utilizados no Brasil para geração de energia elétrica - Operação.

\begin{tabular}{cccc}
\hline Combustível & $\begin{array}{c}\text { Quantidade de } \\
\text { empreendimentos }\end{array}$ & Potência (kW) & \% \\
\hline Biomassa & 429 & 8.990 .493 & 28,79 \\
Fóssil & 1045 & 20.753 .350 & 66,46 \\
Outro & 36 & 1.485 .270 & 4,76 \\
Total & 1510 & 31.229 .113 & 100 \\
\hline
\end{tabular}

Fonte: Agência Nacional de Energia Elétrica (2012). Fonte: Atlas de Energia Elétrica do Brasil (2008)

Cocombustão: Esse método propõe a substituição de parte do carvão mineral manuseado em usinas termoelétricas por biomassa. Dessa maneira, reduz-se consideravelmente a emissão de poluentes.

Resíduos sólidos urbanos: Podem ser utilizados por meio da queima direta e é uma forma já adotada em países desenvolvidos. O lixo pode conter até 705 materiais com potencial energético.

\section{Processos termoquímicos}

Pirólise: Através dessa técnica, a biomassa é submetida a extremas temperaturas sem a presença de oxigênio, acelerando a decomposição da mesma. O que sobra da decomposição é uma mistura de gases, líquidos (óleos vegetais) e sólidos (carvão vegetal). Esse processo se descreve pela queima e degradação da biomassa a temperaturas de $500{ }^{\circ} \mathrm{C}$, na ausência total de oxigênio. Um exemplo de produto produzido a partir da pirólise é o bio-óleo.

Gaseificação: Transforma a biomassa em combustível na forma gasosa tendo como produtos primordiais o hidrogênio e o monóxido de carbono, manipulado na geração de energia e indústria química. Assim como na pirólise, aqui a biomassa também é obtida na ausência do oxigênio, sucedendo como produto final um gás inflamável. Esse gás ainda pode ser filtrado, tendo em vista a retirada de alguns componentes químicos residuais. A diferença básica em relação à pirólise é o fato de a gaseificação exigir menor temperatura e resultar apenas em gás.

\section{Processos biológicos}

Fermentação: Desintegra a biomassa com uma bactéria anaeróbica, para que se transforme uma mistura abrangendo metano e dióxido de carbono. É utilizada para a geração de eletricidade e muito utilizada em indústrias para purificação de lixo e esgoto.

Resíduos vegetais: Podem ser transformados desembaraçadamente em energia devido à baixa umidade e à facilidade de processamento. A sua disponibilidade é sazonal e necessitam de armazenamento, e isso pode transformar os processos de fermentação.

Digestão anaeróbia: Neste cenário, o processo de decomposição da biomassa é realizado por bactérias e na ausência de oxigênio. É extremamente utilizado na transformação de lixo urbano e agrícola em combustível.

Resíduos animais: O processo indicado para esse tipo de resíduo é a digestão anaeróbica.

\section{Produtos derivados da biomassa}

Biogás: É o gás que é gerado durante o método da digestão de biomassa na forma anaeróbica. Pode tanto ser usado em fogões como para a geração de energia. Os resíduos da biomassa podem ser apontados de tais maneiras: resíduos sólidos urbanos, resíduos animais, resíduos vegetais, resíduos industriais e resíduos florestais.

Bio-óleo: Líquido negro obtido por meio do processo de pirólise cujas destinações principais são aquecimento e geração de energia elétrica.

Bioetanol: Constituído no Brasil, tem como base principal o sumo extraído da cana-de-açúcar. Há países que empregam milho, caso dos Estados Unidos (maior produtor mundial de etanol), e beterraba (França) para a sua produção. O sistema à base de cana-de-açúcar empregado no Brasil é mais viável e seu produto também mais utilizado em veículos do que o americano e francês.

Carvão vegetal: Resultado da carbonização da lenha.

\section{Discussões}

\section{Vantagens como fonte energética}

A biomassa usada de forma correta pode ser uma ótima opção energética, é renovável e gera poucas quantidades de poluentes. Em uma usina de álcool, por exemplo, os resíduos, no caso, o 
bagaço da cana-de-açúcar, podem ser utilizados para produzir biomassa e energia.

A geração de energia através da biomassa pode contribuir para a diminuição do efeito estufa e do aquecimento global, com isso gerando energia e sendo utilizada nos meios de transportes.

\section{Vantagens e desvantagens}

Vantagens

- Baixo custo de aquisição;

- Não emite dióxido de enxofre;

- As cinzas são menos agressivas ao meio ambiente que as provenientes de combustíveis fósseis;

- Menor corrosão dos equipamentos (caldeiras, fornos);

- Menor risco ambiental;

- Recurso renovável;

- Emissões não contribuem para o efeito estufa.

Desvantagens

- Menor poder calorífico;

- Maior possibilidade de geração de material particulado para a atmosfera - isso significa maior custo de investimento para a caldeira e os equipamentos, para remoção de material particulado;

- Dificuldades no estoque e armazenamento.

A constante busca por alternativas eficazes de produção de energia é essencial para a população em geral, principalmente na atual sociedade, na qual cada vez mais aumenta o consumo de energia. Diante dessa submissão de recursos, surge então a necessidade de diversificar a utilização das fontes de energias. Uma boa opção energética é a biomassa, que pode ser uma boa opção energética, pois é renovável e gera poucas quantidades de poluentes, além de colaborar para a amenização do efeito estufa.

\section{Conclusão}

A energia obtida através da biomassa é uma fonte renovável de energia que, assim como outras fontes renováveis, tem menor impacto ambiental, porém quando utilizada de maneira errada pode não ser tão vantajosa quanto parece. Encontramse algumas dificuldades em seu armazenamento e no seu transporte, que são dos motivos porque ela é pouco utilizada. Seria muito bom para o meio ambiente que se investisse muito mais nas fontes renováveis de energia, pois as fontes não renováveis de energia causam impactos no meio ambiente e também na sociedade.

A biomassa pode ser considerada como melhor opção, pois tem maior potencial, que pode garantir o abastecimento energético no futuro.

As conclusões desta pesquisa demonstram que a utilização de biomassa atualmente cresce em todo mundo. De acordo com os resultados do estudo, um número grande de novas grandes instalações, tanto para refinar e processar biomassa como para o transporte de energia (biocombustíveis), e também utilizadas na conversão da biomassa em energia e calor, estão atualmente sendo construídas por todo o mundo.

\section{Referências}

AGÊNCIANACIONAL DE ENERGIAELÉTRICA - ANEEL. Banco de Informações de Geração. 2012. Disponível em: http://www2.aneel.gov.br/ aplicacoes/capacidadebrasil/capacidadebrasil.cfm. Acesso em: 19 jan. 2017.

ATLAS DE ENERGIA ELETRICA DO BRASIL. Fontes renováveis- parte II. Brasília: Aneel, 2008. Cap. 4.

BALEOTTI, L. O lixo que vira luz. Revista Alcoolbrás, v. 133, p. 34-41, 2007.

INNOCENTE, A. F. Cogeração a partir da biomassa residual de cana-de-açúcar - estudo de caso. 2011. $111 \mathrm{f}$. Tese (Mestrado em Agronomia) Universidade Estadual Paulista "Julio de Mesquita Filho", Botucatu, 2011. 